\title{
LA COSMÓPOLIS MONISTA. CINCO TESIS CONTRAHEGEMÓNICAS DESDE UNA BIOÉTICA DEL SUR
}

\author{
THE MONIST COSMOPOLIS: \\ FIVE COUNTERHEGEMONIC THESES FROM A BIOETHICS OF THE SOUTH
}

\author{
Álvaro B. MÁRQueZ-FERNÁNDEZ \\ Universidad del Zulia \\ amarquezfernandez@gmail.com
}

\author{
RECIBIDO: $15 / 10 / 2016$ \\ ACEPTADO: 07/11/2016
}

\begin{abstract}
Resumen: En este artículo se presentan cinco Tesis de crítica contrahegemónica que cuestionan el desarrollo cosmopolita de la racionalidad monista de la Modernidad, en su expansión colonial y deshumanizadora. El mundo de vida de los seres racionales es interpretable a partir de su entorno vital, histórico, cultural y natural. Los efectos perversos del avance del dominio tecnocientífico ha puesto en riesgo, a causa de las hegemonías de poder que sirven de fundamento a los procesos sociopolíticos y económicos del mercado neoliberal y global, las condiciones materiales de reproducción de la vida al negar el thelos de sostenibilidad que permite el reconocimiento de derechos humanos inherentes a la existencia para una evolución equitativa. Desde la diversidad de saberes ancestrales característicos de las culturas latinoamericanas, otras voces se levantan para uso de una hermenéutica heterotópica de la racionalidad en contextos donde los supuestos de otro deber ser se proponen en función de una bioética del Sur: el desafío es hacer viable la emergencia de derechos humanos más cónsonos con la satisfacción de una vida deseada en paz y felicidad, un diálogo que permita la comprensión del mundo de vida donde un buen vivir sea el resultado de una convivencia solidaria con los otros y la naturaleza.
\end{abstract}

Palabras clave: Contra hegemonía, Crítica, América Latina, Bioética.

\begin{abstract}
This article discusses five theses of counterhegemonic critique that question the development of the monistic cosmopolitan rationality of modernity, in its colonial expansion and dehumanizing present. The life world of rational beings is interpretable from their vital, historical, cultural and natural environment. The perverse effects of the advance of techno-scientific domain has jeopardized - because of the hegemonies of power that underlie the sociopolitical and economic processes of the neoliberal and global market - the material conditions of reproduction of life by denying the thelos of sustainability which allows the recognition of inherent human rights to existence for equitable development. From the diversity of ancestral knowledge characteristic of Latin American cultures, other voices arise for the use of a heterotopic hermeneutic of rationality in contexts where the assumptions of another sense of "must" are proposed based on bioethics of the South: the challenge is to make viable the emergence of more consonant human rights with the satisfaction of a desired life in peace and happiness a dialogue to understanding the life world where good living ("buen vivir") is the result of a harmonious coexistence with others and nature.
\end{abstract}

Key words: Counterhegemony, Criticism, Latin America, Bioethics. 


\section{El dominio de la vida a través de una razón monista}

La Modernidad se plantea un proyecto de progreso científico que implica e impone un control o dominio, sobre las condiciones de vida que se producen y reproducen en la naturaleza.

Es un ideal que se encuentra prefigurado en una noción de libertad restringida que rescata para la dignificación de la vida, una forma de elección racional sometida o subordinada al poder de fuerza que se ejerce de acuerdo a los intereses de la Política.

La finalidad de esta ideología de la libertad restringida, es, efectivamente, lograr una correspondencia entre los ciudadanos y la política, a los efectos de que el sistema de poder, es decir, la gobernanza de la gestión pública, pueda inducir los horizontes de comportamiento que se requieren para alcanzar la aceptación del colectivo a la institucionalidad del orden, con la finalidad de organizar y reprimir la participación.

Precisamente, esos espacios de interacciones subjetivas que nutre y expande las prácticas sociopolíticas de la liberad y hacen viable a través de la crítica las transformaciones de forma y de contenido de los poderes de la política, presuponen una precomprensión del sentido de la vida que obtienen y reciben por parte de los actores: el universo de los valores culturales implícitos en el acontecer cotidiano de la vida ciudadana.

El intento y los esfuerzos coactivos por racionalizar el mundo de la vida de acuerdo a un universo cerrado y estático, que restringe la interacción de las subjetividades, tiende y propicia sistemas de exclusión que por un lado, vienen a determinar una fuerte discriminación entre los sujetos que se ven impelidos a quedar fuera del sistema por carecer de las identidades que los legitiman en el orden de la política; y, por otro lado, sufren una inclusión perversa al terminar sometidos por el sistema de fuerza que los absorbe y que en cuanto tal, busca la reproducción de sus intereses hegemónicos.

Esta postura de la Modernidad niega ${ }^{1}$, evidentemente, el plano de la mínima coexistencia donde el derecho a la vida debe ser un derecho inalienable de la existencia, puesto que en el nivel ontológico, la vida no puede ser susceptible de negación o coacción. Es un derecho de asumir la libertad desde cualquier punto en donde la Vida es necesaria apropiarla materialmente para su óptimo desarrollo. Este tipo de correlación entre la Vida y el orden subjetivo que la dota de sentido humano, debe generar el reconocimiento de que todos los seres vivos

\footnotetext{
${ }^{1}$ Lanceros, P (2006). La modernidad cansada y otras fatigas. Biblioteca Nueva, España.
} 
son sujetos de derechos que les permitan la sostenibilidad en el mundo de la existencia racional de su naturaleza originaria: un ser pensante.

La Modernidad, no se plantea este tipo de cuestión ontológica y filosófica que hace posible pensar el mundo desde otras posturas cognitivas de interpretación, donde el sentido de la existencia transcurre entre múltiples formas alternativas de evolución extremadamente complejas.

No es posible considera un principio universal de identidad o igualdad monista, que pueda considerar como válida la premisa de que la dialéctica inherente a la existencia en su complejidad infra/trans/plusistémica, puede terminar regulada y controlada por un sistema monista expresamente estructurado por el orden lógico de la racionalidad objetivante e instrumental. Nos encontramos con la necesidad de oponer y contrastar la postura tecnocientífica de las ciencias proyectada por la racionalidad Moderna, en cuanto que ésta forma parte hegemónica del uso del conocimiento tecnológico que considera irrelevante el universo sensible y valorativo de la experiencia racional del pensamiento. Puesto que es desde la experiencia vitalista que se hace posible comprender el sentido de la existencia como fenómeno de la Vida en su multiversidad $^{2}$. Se debe plantear una concepción bioética de la política que efectivamente responda a las condiciones genéricas del desarrollo ser social de la humanidad, en la perspectiva comunal de sus derechos a los bienes para todos.

El esfuerzo tecnocientífico por lograr escenarios de más individuación para represar los colectivos humanos, tiende a considerar el sustrato antropológico de la especie humana como idéntico a sí mismo según un universo o patrón racional que los unifica; esto sería, en perspectiva fenomenológica y dialéctica, inviable como un proyecto conclusivo que pretende unificar en un mismo thelos la Historia de la humanidad, como si por pertenecer todos a una misma especie biológica, fuese suficiente tal supuesto para considerar a la humanidad como una mathesis universalis. Tal concepción de la vida de la especie humana y del resto de los seres vivos de la naturaleza, bajo la presunción de que todo es una sólo unidad, racional o pensante, significa, un intento de síntesis, reducción y restricción ontológica, donde los seres humanos serían desprovistos de su libertad y formas subjetivas de valoración, a partir de las cuales el sentido de la existencia adquiere sus significaciones en el contexto de las prácticas políticas que le permiten su auto transformación económica y social.

Los efectos invasivos de la racionalidad monista en el mundo de vida la existencia de los seres humanos, a través del control y dirección tecno-científica

\footnotetext{
${ }^{2}$ Morin, E y Le Moigne, JP (1999). L' intelligence de la complexité. Épistémologie et pragmatique. Colloque de Cerisy, Edtions de l'Aube, Paris, 2007.
} 
de las conductas y hasta de las voluntades autónomas, representa un ámbito de la coexistencia de los seres humanos que finaliza tergiversado y contrapuesto a los proyectos de vida que tienden a un complejo de relaciones y correlaciones, sin los que no es posible garantizar el sentido de los modos de convivencia alternativos en equivalencia con el mundo de la Naturaleza ${ }^{3}$.

Este modelo de racionalidad capaz de establecer un status dominante respeto a los espacios de libertad como práctica del sentido de la existencia, termina por instituirse en un centro de poder anárquico que disminuye o elimina la capacidad de reflexión, crítica, disensual, sobre los sistemas de presión y coacción de la política individualista y de la economía de mercado. El conocimiento científico funda un principio de realidad en nombre del que toda acción de la tecnología interactúa para controlar y manipular las leyes de la naturaleza y de los seres vivos, es una justificación a priori del valor de ese conocimiento en cuanto que es capaz de lograr las rectificaciones o determinaciones por medio de las cuales la vida en la naturaleza puede terminar regida por comportamientos que se inducen o se programan, fuera de cualquier juicio de valor respecto a la legitimidad o legalidad de tal modo de pensamiento racional, entre lo real y lo ideal. La escisión del mundo entre lo científicamente objetivo y no-objetivo, es irrefutable experimentalmente, es una tautología lógica que no admite reparos o cuestionamientos. Precisamente, porque se renuncia a cualquier tipo de valoraciones éticas o morales toda vez que el conocimiento objetivo no es susceptible de interrogantes bioéticos en correspondencia a sus fines.

La ciencia y la tecnociencia invaden y represan los espacios de coexistencia de la vida que forman parte de sistemas abiertos de interacción y correspondencia, que no pueden interpretarse por separados, sino en conjunto. Sobre todo, en lo que se refiere al mundo de vida de los seres vivos, en especial el de los seres humanos, que es emergente de acciones e intenciones prácticas de la conciencia y la razón como forma de comunicación y comprensión de la realidad.

Las prácticas racionales son formas discursivas del uso de representaciones y símbolos para acercarnos a las realidades del mundo como mundos diversos y desfronterizados que rechazan la imposición de cualquier tipo de normas, cuya función reguladora tiende a una totalidad del sistema que niega su relación ecosistémica interna y externa. El rechazo a este tipo de orden de poder de la racionalidad para auto constituirse en el mundo objetivo las sensibilidades, percepciones, representaciones subjetivas de los seres humanos, pone en

\footnotetext{
${ }^{3}$ Morin, E (1986). La Naturaleza de la Naturaleza. Método, 1. Cátedra, España.
} 
denuncia un actuar político que buscar restringir y censurar la libertad de los seres para su auto transformación histórica y cultural.

\section{Lógicas instrumentales de las tecnociencias y discurso deconstructor}

Nos encontramos un dilema entre los fines de la investigación científica en su rol por el control de la vida de los seres vivos y del planeta, y los intereses que resultan de un modo de producir el conocimiento científico que excluye de sus principios aquellos de responsabilidad ética respecto al uso del conocimiento objetivo. Los avances en la forma de control tecnológico sobre la gestación, desarrollo y culminación de los sistemas de vida, es reflejo del modo en que las economías de la producción de las tecnologías y sus respectivos mercados, están en capacidad de impactar el orden de la existencia y restringir sus autonomías y libertades.

Precisamente, nos encontramos ante una concepción histórica del mundo que surge de una aceptación del poder de la ciencia y sus tecnologías, como las únicas autosuficientes para dirigir y ordenar el mundo con arreglos a los fines del poder que viene derivado de la producción del conocimiento. Y que en muchos casos es una concepción del poder que hace caso omiso a las críticas que provienen del mundo de vida de quienes se resisten a su sometimiento. Es así que resultan muy cuestionable esas lógicas de mercado que consideran al sujeto exclusivamente como objeto de producción y de consumo. ${ }^{4}$ Y que en su capacidad para intervenir en el mundo de las subjetividades se proponen falsificar la comprensión de la existencia desde un deber ser que se pronuncia y acepta valores de vida adeptos al orden de las lógicas del poder y a tipos de razonamientos mucho menos dialógicos que impiden aclarar los fines de las toma de decisiones que políticamente no siempre responden a los intereses generalizables de las mayorías.

Los desarrollos de la ciencia se pueden leer en la perspectiva de un acto invasivo en el ámbito más inconsciente de la naturaleza de la vida. Un tal momento interventor es cuestionable porque incide en una directa inducción instrumental que hace manipulable las leyes de naturaleza y de los seres vivos, socavando el ser biótico que tiende por medio de sus propias auto transformaciones, a perder el sentido evolutivo que requiere la especie humana, en este caso, para optimizar las instituciones de más perfectibilidad en el mundo de la polis.

\footnotetext{
${ }^{4}$ Hinkelmmeet, F y Mora. H (2005). Hacia una economía para la vida. DEI, Costa Rica.
} 
La potencia interventora, repetimos, para instituirse el orden lógico de una tal racionalidad que comprende el mundo como un monismo cultural e histórico ${ }^{5}$, insiste en dotar de una estructura dimensional a la diversidad de la naturaleza humana y a la Política. La asunción de un modelo de desarrollo científico y humanístico muy contrario a los bienes en común de la sociedad como un colectivo generalizable, donde los intereses impuesto por la racionalidad del mercado tecnificado, crea identidades que cosifican los intereses individuales de cada una de las personas.

Desde una perspectiva intercultural de los saberes es inviable un modelo u orden lógico con tales estructuras de coacción, pues entra en detrimento de los espacios de la naturaleza intersubjetiva particulares de cada cultura para lograr sus fines y generar sus propios medios para alcanzarlo ${ }^{6}$. La uniformidad que postula la ciencia, en sus proyecciones de dominio de la totalidad de la vida humana, a partir de patrones de control que le permite fortalecer y consolidar en la sociedad los mecanismos de su propia reproducción, atenta contra un genuino principio de autonomía y libertad subjetiva de los actores sociales del colectivo humano. El propósito de anular los ámbitos de encuentros y re-encuentro entre los discursos disidentes y de dialógicos interesados por las prácticas emancipadoras del poder, es un acto fallido puesto que la crítica contrahegemónica busca resituar la alteridad desde un auténtico convivium de intereses comunes. No es la ciencia y sus tecnologías de producción y de consumo, las que podrán dirimir el complejo proceso de conflictividad que se debe resolver o solventar desde la voluntad de autonomía de los participantes en la política.

La Modernidad proponer como viable la obtención de los beneficios consagrados a partir de una concepción de las ciencias cuya punta de lanza, encuentra su único respaldo en los procesos lineales del desarrollo tecnocientífico, en consonancia con la idea pragmática del control y la sumisión. No se hace necesario reconocer el compromiso ético inclusivo en el uso racional del poder de las tecnologías al aplicarlas a la construcción de modelos de comportamientos humanos subordinados al control objetivo de la racionalidad experimental. Ello ha traído consecuencias negativas por la manera de aplicar y hacer operativos los modelos de reproducción de la naturaleza para poder explotar sus riquezas en pro del bien de las élites del poder.

\footnotetext{
${ }^{5}$ Cfr. Márquez-Fernández, A (2013). “Crisis hegemónica neoliberal y filosofía contrahegemónica emancipadora. De la racionalidad del capital a la razonabilidad del buen vivir", en: Hidalgo, G y Márquez-Fernández, A (Eds.). (2013). Contrahegemonía y Buen Vivir. UAM, México, p. 82

${ }^{6}$ Fornet-Betancourt, R (2001). La transformación intercultural de la Filosofía. Desclée, Bilbao.
} 
Una comprensión de los roles del dominio tecnológico de las ciencias, incapaz de reconocer el sustrato sensible de la vida humana intersubjetiva ${ }^{7}$, es el punto de cuestión inicial para problematizar el sentido antropológico de los destinos de la humanidad, que marca la Historia de su evolución y desarrollo. La reflexión y la crítica axiológica permiten tener presentes esos universos de eticidad y moralidad que deben contextualizar las responsabilidades finales del uso de control de las tecnociencias sobre los mundos de vida de los seres humanos.

Las reinterpretaciones que requiere la concepción racionalista de la cosmopolis monista, parte de un discurso de crítica que permita debatir el sentido reductor de la racionalidad a unos fines preconcebidos por los intereses de la ciencia como forma de apropiación de la realidad. En particular, este principio de intervención depredadora, tiene un alcance axiológico cuya repercusión es extrema en el ámbito de vida donde se deben resolver las necesidades propias de la vida pública y donde la responsabilidad de optar por fines y bienes en común, es una responsabilidad valorativa de $\operatorname{todos}^{8}$. Se requiere, entonces, un discurso deconstructivo de las estructuras hegemónicas de la racionalidad monista con la finalidad de hacer visible y exponer en consecuencia, el orden de dominio coactivo que vendrá a favorecer ese tipo de sociedad asociada a los intereses de la producción del conocimiento tecnocientífico y sus mercados de consumo.

Los discursos contrahegemónicos generan en sus actuales horizontes fuertes críticas políticas e interculturales que permiten deconstruir la hegemonía de la racionalidad monista de la Modernidad, cuya finalidad ha sido constituirse en una episteme que logra sintetizar, a través de los valores absolutos de sus prácticas, la unidad racional que hace posible avalar el imperio del uso de las tecnologías como referente deshumanizador de las condiciones de vida de los seres humanos.

Pero, precisamente, el riesgo que subyace en la tesis hegemónica de la tecnociencia, es que la bonanza idealizada de los beneficios de las tecnologías en los sistemas de control político y socio-económicos, en manos de las élites políticas y económicas neoliberales, pueda terminar deslegitimada por parte de quienes no se ven identificados entre los fines de tal rentabilidad. Esto coloca de relieve que sin la puesta en práctica de juicios éticos y morales acerca de la pertinencia de esos fines como un bien en común para todos los seres humanos, no es posible discernir el hipotético ideal de justicia pública que se declara como el resultado óptimo de una ciencia al servicio de la humanidad.

\footnotetext{
${ }^{7}$ Lévinas, E (1991). Entre nous. Essais sur le penser-à-l'autre. Grasse, Paris.

8 Jonas, H (1975). El principio de responsabilidad: Ensayo de una ética para la civilización tecnológica. Herder, Barcelona.
} 
En sí misma la rentabilidad, en términos de derechos humanos, que pueda surgir de la aplicación de las tecnologías o ingeniería social al mundo de vida, no puede sostenerse en base a criterios de producción y reproducción de la economía como fuente exclusiva del capital. Es una comprensión de la vida en unos términos depredadores que, por supuesto, entran en contradicción con los principios esenciales de la existencia de la Vida. Pues, el universo de la vida es mucho más rico en sus valoraciones culturales, toda vez que los sistemas de vida son abiertos e interconectados. Todo lo que fluye y refluye en el caos de las incertidumbres no está exento de vinculaciones con los principios universales de la vida y de las éticas públicas y del bien en común.

Las concepciones empiristas de la racionalidad tecnocientífica, tienden a considerar que la razón sólo se corresponde al uso de la fuerza para imponer universos de dominios que van de lo simbólico a lo factual, la intención es de constituir un orden de normas que permita estructurar las semiosis de la realidad con el fin de cohesionar las vidas subjetivas a un único patrón de sistemas de sentidos y significados. La condición opresiva de este tipo de concepción racional sobre el mundo de vida valorativa, sensible, estético y ético, es indiscutible pues se trata de estructuras y superestructuras que en su decurso terminar interiorizadas por los seres humanos cooptados.

Hacer posible la superación de este status hegemonizo de la razón requiere de una crítica muy profunda que debe tomar en cuenta la evolución histórica de tal modelo que no puede quedar disociado del modo de la producción de la vida material. Pues, precisamente, se trata de comprender esa correlación entre historia y cultura de la que provienen los múltiples sentidos de la realidad. La inferencia de esta racionalidad para infiltrar los tejidos sociales sin dejar al margen espacios de resistencia, en casi absoluta. Ello contribuye notablemente a acrecentar su imperio respecto de otras formas de racionalidad que estiman el desarrollo de las tecnologías, más en consonancia con las satisfacción de necesidades donde los derechos humanos de todos a los bienes se legislan desde una moralidad pública que sirve de escenario para dar fundamentos a las condiciones materiales de la justicia social y económica.

La presencia de esta otra forma de racionalidad, crítica y deconstructiva, que surge de correlaciones socio-políticas más humanistas, es consciente de que los seres humanos deben coexisten según normas de valor que se consensuan por principios éticos de bien en común y solidarios; pertinentes para garantizar la sobrevivencia de la vida en la naturaleza. Lo que viene a significar que el poder de la racionalidad busca su contextualidad axiológica toda vez que proviene de un humanismo cuyo respaldo, en todo momento, es la consecución de la reproducción material a la vida desde la justicia equitativa. 


\section{La complejidad senso-racional de una bio-ética cosmopolita}

La tradición racionalista de la cultura occidental poco a poco ha venido desplazando el mundo de vida sensible y estético del pensamiento de la experiencia racional que se ejercita a partir de la construcción objetiva del conocimiento. Este alejamiento del ser de la naturaleza sensible, emocional y afectiva de la vida impone, sobre todo, un fin que hace que la distinción y diferencias del espacio humano pierda la mayoría de sus singularidades; es decir, las formas por medio de las cuales las identidades culturales que permiten valorar el thelos de una sociedad, son necesarias tenerlas presentes en la prácticas cotidianas en nuestra relación con el mundo de la vida y de la naturaleza. Una desigual correlación de dos mundos que se complementa y que es a causa de estas alteridades fenoménicas que el ser de la vida se hace y realiza en su despliegue existencial junto a otros seres.

Mirar el mundo es más que un concepto lógico o numérico de la racionalidad instrumental que es capaz de transformar el mundo en cosa o entes utilitarios o funcionales para resolver circunstancias inmediatas del mundo de las satisfacciones y necesidades. La comprensión del mundo de la vida requiere de un encuentro o aproximación hacia un cosmos sensible de humanización que se socializa a través de correlacionalidades ${ }^{9}$. Una cultura nace y se desarrolla en sostenibilidad con principios singulares o particulares de sus prácticas y usos de valor en su intención de universalizar o totalizar proyectos de convivencia, donde no se nieguen las relaciones sensibles y afectivas que podemos compartir entre nuestras vivencias y las leyes de la naturaleza. Es urgente contar con biopolíticas que permitan garantizar el equilibro entre los múltiples mundo de vida posibles para una coexistencia compartida.

No se puede seguir dejando al margen de una reflexión crítica y consciente de las experiencias sensibles y afectivas que se deben desarrollar correlativamente con el mundo objetivo que somos capaces de crear a través de la tecno-ciencia. El fenómeno de la sensibilidad por medio del que se capta la aparición de la realidad como instancia vivencial que nos hace consciente de la relación entre el cuerpo y la naturaleza, no está divorciado de una contemplación-comprensión de la naturaleza de la vida en cuanto que manifestación compleja de experiencias que se asocian y relaciona entre sí para poder autogenerar entropías a favor de prácticas biopolíticas alternativas al poder de dominio que se ha construido desde las muralla del monismo científico.

\footnotetext{
${ }^{9}$ Ortíz-Osés, A (2003). Amor y sentido. Hermenéutica simbólica. Anthropos, Barcelona.
} 
Es insostenible una separación cartesiana de los mundos objetivos de su remitente corporal sensible y subjetivo, todos ellos son sucedáneos de las correlaciones entre vidas en curso de emergencia y fines, que se labran intersubjetivamente en torno a universos aleatorios que se cogestionan para su desarrollo diferencial pero a su vez complementario. Poder llegar a interpretar que el mundo no es reducible a lo inmóvil o estático por el ejercicio de una racionalidad monológica que indaga sus procesos dinámicos para determinarlos desde una economía política de la producción de objetos, es denunciar el proyecto de irracionalidad que deshumaniza a las culturas. Nuestra relacionalidad sensible y afectica con el mundo no puede deslastrarse de los entornos donde los equilibrios o desequilibrios producen las tendencias de los cambios. El mundo responde permanentemente a las leyes del devenir y la racionalidad de los seres humanos no puede sujetarlo a un control instrumental pues las consecuencias son funestas y trágicas. Se requiere de una interpretación o hermenéutica de las intersubjetividades para poder dotar de un sentido ético a las relaciones opresivas y de explotación que sufre la naturaleza del mundo de vida de la humanidad, igual se puede afirmar con respecto a la Naturaleza como mundo de existencia orgánica para la vida de todos los seres.

Las equivalencias o analogías entre racionalidad y sensibilidad son impropias desde un punto de vista simétrico de posibles experiencias sensibles que permitan organizar la sociedad por estamentos. Las dos formas de intelección del mundo no están predeterminadas por un modo único de desarrollo o evolución. Se complementan pero a la vez sus necesarias diferencias son válidas para poder dar sentidos a las respectivas experiencias de pensar y sentir el mundo de la vida. Siendo que, precisamente, la manifestación por medio de la cual el mundo se asume como sentido y representación es a través del símbolo y de la imaginación y, quizás, posteriormente a través de la lógica y sus tecnologías de poderes. Pero, en esto consiste la discusión entre la comprensión ética de un mundo de mundos posibles abiertos a las prácticas de valores autónomos y libertarios referidos a derechos humanos custodios del bien en común, y su vinculación directa con el orden de constitución de la realidad objetiva del mundo a través de las ciencias positivas.

La relación entre los valores de la bioética y la pluralidad de intenciones intersubjetivas de las que el cosmos de la sociopolítica de los mundos de vida forma parte, es la mejor posibilidad para generar los contenidos de un discurso crítico sobre los procesos de dominio del poder de la ciencia que impiden o restringen la dialogicidad mínima para la obtención de consensos y arbitrajes para resolver la conflictividad entre seres racionales. Esto es decisivo y fundamental para que el universo axiológico que sirve de status a la racionalidad 
objetiva pueda propiciar una hermenéutica desde las heterotopías de las experiencias subjetivas de los mundos de vida, y así llegar a cancelar el orden de coacción, explotación y reproducción de los sistemas de control humanos.

La propuesta reclama la recuperación y recreación de la racionalidad desde la perspectiva humanista de una ética cuyo principio esperanza ${ }^{10}$ se basa en un compromiso con el tiempo presente en su visión de futuro posible. El ideal utópico de la ética en tanto que desea pensar y sentir el mundo como encuentro entre otros para la realización del bien en común y la paz solidaria, va a suponer que los discursos de la racionalidad no pueden seguir profesando una doctrina de la apropiación y explotación de las condiciones materiales de la vida. Menos todavía, de una concepción del poder que sólo proyecta relaciones de fuerzas que invalidan las libertades de los sujetos en la vida de la política. El presente de la humanidad requiere de una epifanía humanista que surge de un lúcido cuestionamiento de los valores positivistas del poder tecnificador de las ciencias, ante una diversidad de expresiones culturales que permanentemente revitalizar el sentido innovador con el que los sujetos que intervienen en sus historias de vida, dan y ofrecer los cambios cualitativos de las experiencias de la racionalidad histórica. Las relaciones humanas no se pueden sostener bajo la mirada escrutadora de normas instrumentales que cosifican el sentido de la existencia.

La razón racionalista no es una propuesta efectivamente filosófica que se encuentre en condiciones de interpretar que la inmanencia del sujeto en el desarrollo biopolítico del mundo de vida pasa, en todos los casos, por un plexo de interconexiones internas y externas que son causa eficiente del modo en el que la humanidad consustantivamente regenera la naturaleza de la Vida. Pero esos cambios que crean una permanente fractura o disipación de la estructura de dominancia es importante entenderlos en cuanto que aspectos de fenómenos dialécticos y holísticos de la pluralidad que es intrínseca a las prácticas deconstructivas de la racionalidad. Un giro por medio del cual se revierte el orden lineal al que apunta regularmente la coacción de la tecnificación del mundo, formas de autodefensa hacia espacios móviles donde el universo humano discurre sin el peso de los modelos de la producción del conocimiento objetivo de la realidad.

\footnotetext{
${ }^{10}$ Bloch, E (2007). Principio Esperanza. Vol. I, Trotta, Madrid.
} 


\section{Hacia otros espacios de un convivir para una bio-ética comunal}

Las prácticas éticas se relacionan directamente con estructuras lingüísticas de la racionalidad de la filosofía práctica. Es decir, sus referentes son sujetos destinatarios de normas de valor cargadas de una presunción particular que se desprende del universo fáctico de la vida, y, también, de otros contenidos de valor formales y simbólicos, en concomitancia con el deseo universal de un bien en conjunto y compartido. Por consiguiente, se puede considerar que existe una ética que nos hace comprender el mundo de vida como un mundo de valores que considerados como bienes particulares y universales, son preponderante a la hora de elegir, opinar, dialogar, en sistemas de convivencias en libertad y justicia ${ }^{11}$.

La ética presupondrá valores ideales y utópicos, pero, a su vez, valores subjetivos que tienen su origen en los sistemas de intercambios y de comunicación de los seres humanos. Somos portadores y transmisores de valores, quizás, el principal, es el valor que le signamos a la racionalidad situada en contextos axiológicos que la hacen interpretable. Los valores que están implicados en los principios para la acción ética, se proyectan a través de relaciones humanas que se hacen afectivas por medio de lo lingüístico que permite denotar y connotar el thelos de esas estructuras normativas de valoraciones prácticas más en consonancia con una comprensión del nivel de dignidad que merece la vida. Es lo que hace, por consiguiente, a la ética un referente indispensable para comprender el sustrato de las intersubjetividades que le confiere mejores contextos para los actos de Justicia tan necesarios en los sistemas del mundo de vida de los seres humanos.

Se trata acá de visualizar e insistir en lo impropio y absurdo que es someter las esferas de las intersubjetividad, germen de las valoraciones genéricas del deber ser, acerca del mundo de vida entre unos y otros, a las coacciones y hegemonías que toman fuerza en las pretensiones del sentido totalitario de la racionalidad monista como el legítimo orden del conocimiento objetivo, en su conexión con las experiencias hermenéuticas del sujeto.

La exclusión que sufre la ética de los discursos de las ciencias positivas, y, sobre todo, de los discursos de las tecnologías del poder, es nefasta desde todo punto de vista, pues se pretende validar las relaciones entre los espacios de la razón práctica en el reconocimiento de los contenidos de valor, que impulsan la identificación del status material de los valores, con el uso pragmático de la fuerza de la racionalidad que cosifica el sentido sensible de la existencia. La ficción científica de una unidad del discurso a partir de las síntesis simbólicas

${ }^{11}$ Aranguren. JL (1996). Ética y política. Biblioteca Nueva, Madrid. 
que generan y posicionan los códigos del cientificismo al interior de las sociedades del consumo y de la conflictividad democrática promovidas por las élites y clases en el poder; en ningún caso pueden considerarse como un código ético de convivencia que deba continuar prescribiendo los destinos globales de la humanidad.

Los discursos de las biopolíticas del poder y sus inferencias tecnológicas ${ }^{12}$ en la regulación normativa de las conducciones sociales, a través de los valores de la idolatría del mercado y el fetiche del consumo, cada vez más son cuestionables en su intento de cohesionar los espacios públicos de convivencia ciudadana donde el rol protagónico de los sujetos se enmarca en nuevas movilidades de acciones humanistas que propenden a la construcción de un tejido intersubjetivo, más en alteridad con ellos y la naturaleza como instancia de coexistencia de los sujetos vivos.

La bioética se inserta en el espacio público que ha venido siendo colonizado por la hegemonía de las tecnologías en el ámbito de vida intersubjetivo donde reside la voluntad de poder para resistir a las subordinaciones de un sistema político controlado por la racionalidad de la estructura de producción y reproducción del mundo objetivo. Se interviene el espacio público donde el registro del ser social toma carta de identidad de ciudadanía política en franca beligerancia de cara a la estructura de poderes centralizados por la racionalidad estratégica del discurso de la racionalidad positivista.

Los roles a cumplir por la bioética ${ }^{13}$ parten de principios que si bien se reconocen válidos por su universalidad, es decir, logran alcanzar un desiderátum simbólico que puede ser representado desde el mundo de la vida cotidiana como necesario y deseable posible; también, son roles que en su práctica intersubjetiva logran contextualizar el sistema de valores que se deben cumplir prácticamente en beneficio de un bien justo en comunicación con sistemas de convivencias reciprocas.

Por consiguiente, el sentido y sentimiento con el que se instituye el espacio público entre los seres humanos gobernados viene a demostrar que los contenidos de valor universal de las normas bioéticas son contenidos materiales contextualizados cultural e históricamente por prácticas de vida, que están significadas por la subjetividad de los sujetos en su expresión y convivencia social. Por tal motivo, el Estado debería resultar no sólo un reflejo de este nuevo orden de valoraciones biopolíticas de los poderes que subyacen en los sistemas

\footnotetext{
${ }^{12}$ Foucault, M (2004). La naissance de la biopolitique. Cours au Collège de France (1978-1979). Haute Étude, Gallinard, Paris.

${ }^{13}$ Andorno, R (2012). Bioética y dignidad de la persona, $2^{\text {a }}$ edición, Madrid, Tecnos.
} 
hegemónicos, sino que al hacerse emergentes estas alteridades del poder se obtiene otros registros materiales para la recreación de la vida en su universo de existencia que, a su vez, permite una apropiación del carácter liberador que ejerce el discurso de la bioética en la cosmopolis monista que esclaviza la vida social y política de los seres humanos.

La vida debe ser considerada desde una perspectiva existencial que nos permita valorar su trascendencia en el curso de una concepción del mundo donde nuestra pertenencia es comunal, coimplicativa, puesto que todos somos seres, sujetos, ciudadanos, interesados en la construcción humana de la historia y sus saberes. A todos nos toca formar parte de esta experiencia convivida que potencia la necesidad de una conciencia que es siempre una emergencia interiorizada que logra su presencia real ante los otros por medio de un coexistir que los une solidaria y fraternalmente. El mundo de la naturaleza humana ya no se concibe en términos de un conflicto permanente de intereses y poderes porque ya no se piensa bajo las categorías de una racionalidad con arreglo a fines que entra en contradicción con las prácticas de justicia y paz para todos.

\section{De la bioética del buen vivir o Sumak Kaway}

Los desarrollos del capitalismo global se basan en agudizar la tendencia de la estructura del mercado como proceso de intercambio y de consumo que se encuentra al servicio de la apropiación de los recursos naturales que hacen viable la existencia de la vida sobre la tierra, y, por, consiguiente, no cesa de degradar la vida de muchos seres humanos que forman parte de este sistema al convertirlos en una mercancía de un modo de un producción que empobrece y deshumanizada.

Las leyes del capital, principalmente, la de la plusvalía es una ley cuyo sentido depredador se hace extensiva al ámbito de la coexistencia de los seres sociales por medio de políticas de gobernanza que se encargan de relegitimar las formas hegemónicas del Estado neoliberal. Los sistemas de valores que sirven de justificación a este modelo de racionalidad instrumental que se hace jerárquica en su monismo cultural, se propone como un ejercicio acerca del sentido y significado de la razón capitalista como única y final ${ }^{14}$. Por supuesto que el acompañamiento compulsivo que permite justificar este dominio de lo racional objetivo sobre la humano subjetivo, viene a responder a todo un sistema

\footnotetext{
${ }^{14}$ Hinkelammerrt, F y Duchrow, U (2003). La vida o el capital, alternativas a la dictadura global de la propiedad, DEI, Costa Rica.
} 
de valoraciones éticas que sirven de soporte ideológico para que se puedan cumplir los fines de la economía de mercado que no puede dejar de ser el centro de control de los poderes de tal modelo represivo de la racionalidad capitalista.

Es un proyecto doctrinario de vida que se presenta autosuficiente frente al que se deben generar alternativas para su cambio sustantivo, es decir, su posible desaparición. Su tendencia es a la unificación del sistema de opresión y reproducción del capital a través de las economías del desarrollo global de capitalismo. La diferencias del otro se subordinan a una igualdad que por medio de la unificación del mercado, falsea y distorsiona las esferas de alteridades en las que los seres representan sus ontologías culturales. Y por lo tanto, el discurso de la racionalidad colonial $^{15}$, presuriza los espacios públicos de los seres humanos hasta logra una atmósfera de tolerancia que les permita de minimizar los antagonismos y disidencias para poder reabsorber sus fuerzas de resistencia y oposición, hacia los procesos de ideologización de la racionalidad capitalista, de la que se presume puede dar respuesta a todas las conflictividades del sistema de la producción de la plusvalía.

Sin embargo, no es así la realidad de fondo de este escenario optimista de las éticas públicas que remarcan con una línea roja el dualismo entre los de "arriba" y los de "abajo" para desarticular el diálogo que proviene de las bases populares y sus movimientos sociales. Las posturas de las éticas públicas que justifican el desarrollo del mercado-consumo en el del capitalismo no median en absoluto por una discusión radical de las estructuras de explotación y así develar el revestimiento que se hacen de sus contradicciones desde los consensos del pluralismo ideológico. Se asolapan las urgencias de ese momento de la dialéctica que niega toda premisa universal del dogma, por una crítica material de la razón universal donde la aparición del sujeto vivo es quien está en condiciones fácticas de recrear el mundo de vida y hacer posible otra comprensión sensible y humanizante de la existencia en el entorno sostenible con la naturaleza.

La tradicional escisión entre ética y política, se concibió en la modernidad con el interés de desplazar cualquier tipo de sistema valorativo que incurriera en los procesos de desarrollo de la economía del mercado, es decir, un mercado donde se privilegia la utilidad del uso y el beneficio del costo, en capacidad directa para sortear el cuestionamiento que subyace en la pregunta ética respecto al bien en común o del prójimo. En la interpretación de la economía política que rige el mundo y lo transforma de acuerdos a los intereses hegemónicos de los fines que determinan las lógicas de la producción del capitalismo, no puede darse

15 Quijano, A (2014). Cuestiones y Horizontes. De la Dependencia Histórico-Estructural a la Colonialidad/descolonialidad del Poder. CLACSO, Buenos Aires. 
desde una ética que sirva de crítica a sus contradicciones más sustantivas en total afectación de la vida humana y de la naturaleza. La ausencia del sujeto intencional es una premisa sine qua non para lograr el desarrollo de sus economías "inclusivas" al sistema de intercambios que los aliena al deshumanizarlos porque los hace objetos de ese mercado de equivalentes en su rentabilidad.

Desde la perspectiva de la bioética intercultural y del buen vivir, sumak kaway, se pueden lograr otras hermenéuticas ${ }^{16}$ mucho más críticas en la interpretación de la realidad hegemónica que se constituye a partir de las fuerzas productivas que se desarrollan y dirigen la economía neoliberal. Su conciencia de biogénesis no es la concepción moderna del hombre como un faber absoluto, gestor de todo orden de vida a su voluntad de dominio. Pues otra comprensión del mundo de vida como bios considera al homo faber correlato de un sistema mucho más complejo y no lineal que estructura y reestructura las interacciones de los elementos que lo componen. Luego, no es admisible presumir que un orden mono-racional de la existencia, puede efectuar la síntesis del orden total que transforma en monismo esa complejidad de autotransformaciones de la naturaleza a las que también está expuesta la naturaleza de la humanidad.

Los nuevos referentes bioético desde el Sur, desde una concepción sumak kaway $^{17}$, nos pueden explicar ese otro sentido de los mundos de vida que remiten a universos de acción y de intención que tienen su origen y desenlace entre las "leyes" de la naturaleza, donde el mundo de la subjetividad tiene mayor estimación para poder comprender las intersecciones entre los cosmos de vida desde otros derechos a la vida que no pueden ser marginados racionalmente. Así el derecho a libertad es extensivo mucho más allá del campo de la racionalidad normativa que presupone la libertad formal como concepto y a la vez, desconoce las experiencias subjetivas de los saberes de una cultura en su interacción con los espacios vitales donde a la naturaleza también se le deben reconocer derechos.

Las características que pueden presentar los principios o normas generales de una bioética del Sur desde la perspectiva del buen vivir, sumak kaway, es que se evalúan la recomposición del sujeto a partir de que sus conexiones con el entorno no vienen regidas por hegemonías racionales que son las que van a determinar los fines de la existencia particular o universal de los sujetos vivos. La producción material del mundo responde a múltiples alternativas de satisfacción de necesidades que se implementan a causa de las propias bifurcaciones caóticas

\footnotetext{
${ }^{16}$ De Sousa Santos, B (2011). "Epistemologías del Sur”, Utopía y Praxis Latinoamericana. 16 (54), pp. 17-39.

17 AA. VV (2010). Los nuevos retos de América Latina. Socialismo y sumak kaway, Quito, SENPLADES.
} 
de los status de las leyes naturales de la existencia, en correspondencia con las formas sensibles de la conciencia para razonar la utilidad que pueden cumplir las objetivaciones que realiza una cultura desde sus historias particulares.

Estas otras formas de prácticas mucho más sensibles y afectivas, estéticas, opuestas al modelo tecnocientífico del desarrollo occidental, sugieren pensar el factum racional no en sí mismo, sino como otra dimensión más de la construcción intersub-objetiva del mundo de la vida. Se nos presenta un estilo de pensamiento mucho más asociado a valoraciones de la producción material de la subsistencia que forman parte de una cosmovisión de la naturaleza del mundo no dualista, sino que, por el contrario, surge de un imaginario de ser en el mundo convivencia y comunal. Lo que, efectivamente, es un claro reconocimiento a la presencia de la alteridad a la hora escenificar la actuación de los sujetos según modos de convivencia y recreación.

Los pueblos originarios de América Latina, en la reflexión crítica y el discurso sobre la biodiversidad de los mundos de vida, retoman el interés por dotar a la bioética de un sustrato de co-existencialidad con otras esferas de la vida que deben formar parte de ese cosmos de valoraciones que hace de un sujeto un ser de vida libre, autónomo y en convivencia. El sentir utopista del buen vivir o sumak kaway, no desmerece su actualidad ya que sin ésta la cosmovisión del mundo como otro posible niega su propia realización de conciencia anticipación temporal, para repensar el mundo desde la razón práctica que hace comprensible admitir el sentido ético de la vida, como principio y valor fundante de la existencia de la vida en todas sus diversidades.

La experiencia filosófica que, desde su tradición griega, asume que el cosmos existe en sus arjés originarios, agua, fuego, aire, tierra, no puede considerarse extraña a la filosofía del buen vivir que consiste en el reconocimiento que hace valida la relación de génesis que existe entre todas las esferas de la vida y las representaciones culturales que no cesan de remitir a esa simbiosis entre el mundo del pensamiento y el mundo de la experiencia racional, que en su objetualidad hace del mundo de vida la instancia primogénita de la creación.

Apenas si en las hegemonías políticas de la modernidad colonial que sufre América Latina, a través de las estructuras que institucionalizan los ejercicios del poder, la impronta del buen vivir puede ser visibilizada en su capacidad para revocar las ideologías positivistas del desarrollo científico, a fin de que la discusión en común-idad para el logro de los derechos humanos concrete el disfrute de los bienes de todos. La bioética desde el Sur, es otra de las praxis alternativas de la filosofía contrahegemónica del buen vivir o sumak kaway, que propone explorar por fuera de la razón instrumental, la vida sensible en su 
autonomía y libertad cultural de saberes, en respeto a los procesos o leyes de sostenibilidad de la Naturaleza. 